\title{
Mucinous adenocarcinona of the appendix
}

Milton Roberto Furst Crenitte ${ }^{a}$, Fernando Peixoto Ferraz de Campos ${ }^{b}$, Patrícia Picciarelli de Lima ${ }^{c}$, Brenda Margatho Ramos Martines ${ }^{d}$, Marcelo Rodrigues Borba ${ }^{e}$

Crenitte MRF, Campos FPF, Lima PP, Martines BMR, Borba MR. Mucinous adenocarcinona of the appendix. Autopsy Case Rep [Internet]. 2013;3(2): 39-44. http://dx.doi.org/10.4322/acr.2013.016

\section{ABSTRACT}

Diagnosis of malignancy in the vermiform appendix is quite rare. The most common histological malignant neoplasia found in this tiny portion of the gastrointestinal tract is represented by the mucinous adenocarcinoma. This entity predominates in males around 50 years of age, and clinical presentation usually mimics or occurs along with an acute appendicitis. Early diagnosis is outside the rule since most cases at this stage are symptomless. The authors present the case of a 59-year-old female patient who looked for medical attention complaining of abdominal pain. Physical examination and laboratory workup were poor in diagnostic findings. The computed tomography images were compatible with the diagnosis of appendicitis and/or appendiceal neoplasia. The patient underwent a laparotomy and right hemicolectomy. The histological examination disclosed a moderately differentiated mucinous adenocarcinoma of the appendix stage $\mathrm{T} 4 \mathrm{a}, \mathrm{N} 0, \mathrm{M} 0$. The patient outcome was uneventful and was referred to an oncological center.

Keywords: Adenocarcinoma; Appendix; Appendicitis; Mucocele; Colectomy.

\section{CASE REPORT}

A 59-year-old female patient sought the emergency department complaining of diffuse abdominal pain during the last 30 days, which had gradually worsened over the last week. She denied fever, nausea, or vomiting. Her past medical history included the diagnosis of hypertension (for which she was taking captopril and hydrochlorothiazide), and had had four cesarean sections. She denied any family history of cancer.
Physical examination revealed an obese patient (body mass index of 32) with blood pressure of $170 / 90 \mathrm{mmHg}$, a regular pulse rate of 72 beats/ minute, and an axillary temperature of $36.7^{\circ} \mathrm{C}$. The examination of the lungs and the heart was unremarkable, while the abdominal examination showed an incisional infraumbilical hernia and a diffuse tender palpation, more pronounced in the right iliac fossa, where the rebound test was negative. Bowel sounds were present and normal.

\footnotetext{
a Department of Internal Medicine - Hospital das Clínicas - Faculdade de Medicina - Universidade de São Paulo, São Paulo/ SP - Brazil.

${ }^{\text {b }}$ Department of Internal Medicine - Hospital Universitário - Universidade de São Paulo, São Paulo/SP - Brazil.

${ }^{c}$ Anatomic Pathology Service - Hospital Universitário - Universidade de São Paulo, São Paulo/SP - Brazil.

d Diagnostic Imaging Service - Hospital Universitário - Universidade de São Paulo, São Paulo/SP - Brazil.

e Department of Surgery - Hospital Universitário - Universidade de São Paulo, São Paulo/SP - Brazil.
}

Copyright $\odot 2013$ Autopsy and Case Reports - This is an Open Access article distributed of terms of the Creative Commons Attribution NonCommercial License (http://creativecommons.org/licenses/by/3.0/) which permits unrestricted non-commercial use, distribution, and reproduction in any médium provided article is properly cited. 
The initial laboratory workup disclosed a mild leukocytosis (leucocytes $12,600 / \mathrm{mm}^{3}$ without shift to the left), biochemical serum analysis within normal range but a C-reactive protein of $185 \mathrm{mg} / \mathrm{dL}$ (reference value $<5 \mathrm{mg} / \mathrm{dL}$ ). The abdominal ultrasound revealed a tubular formation with a $40 \mathrm{~mm}$ thickened wall in the topography of the right iliac fossa, without peristalsis, compatible with the diagnosis of hyperplastic appendicitis. The abdominal computed tomography (CT) showed a thickened formation filled with some heterogenic material, suggestive of a mucocele or carcinoid tumor of the appendix (Figure 1).

The patient underwent an exploratory laparotomy, followed by a right hemicolectomy and the incisional hernia correction. Gross examination of the resected specimen revealed an intestinal segment comprising $18 \mathrm{~cm}$ of ileum, $15 \mathrm{~cm}$ of the right colon, and a dilated caecal appendix measuring $12 \mathrm{~cm}$ in its longest axis, $8 \mathrm{~cm}$ in diameter and $0.4 \mathrm{~cm}$ of thickness. Ileal and colonic mucosae were normal. (Figure 2) The caecal serosa showed an adhered whitish material and a fibroadipose tissue measuring $8.5 \times 7.5 \times$ $2.3 \mathrm{~cm}$ recovered by the peritoneum, which may have corresponded to a peritoneal tamponade. The appendix showed a perforation adjacent to the ostium, where the mucosa was infiltrated in a $2 \mathrm{~cm}$ length in its longest axis, and until the subserosa in depth. The remaining appendiceal mucosa showed a loss of normal pleating.

The histological examination revealed a histologic grade 2, moderately differentiated, mucinous adenocarcinoma with tubular architecture

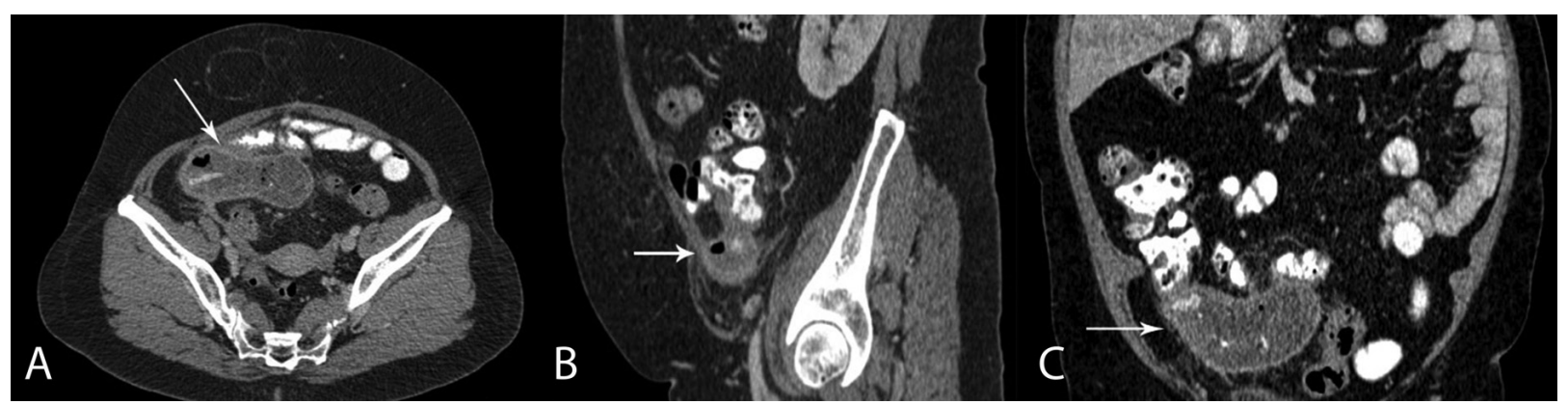

Figure 1 - Computed tomography of the abdomen. A - Axial plane; B - Sagittal plane; C - Coronal plane, showing a dilated caecal appendix, asymmetric and concentric parietal thickening, allowing the passage of a filiform amount of the oral contrast medium.

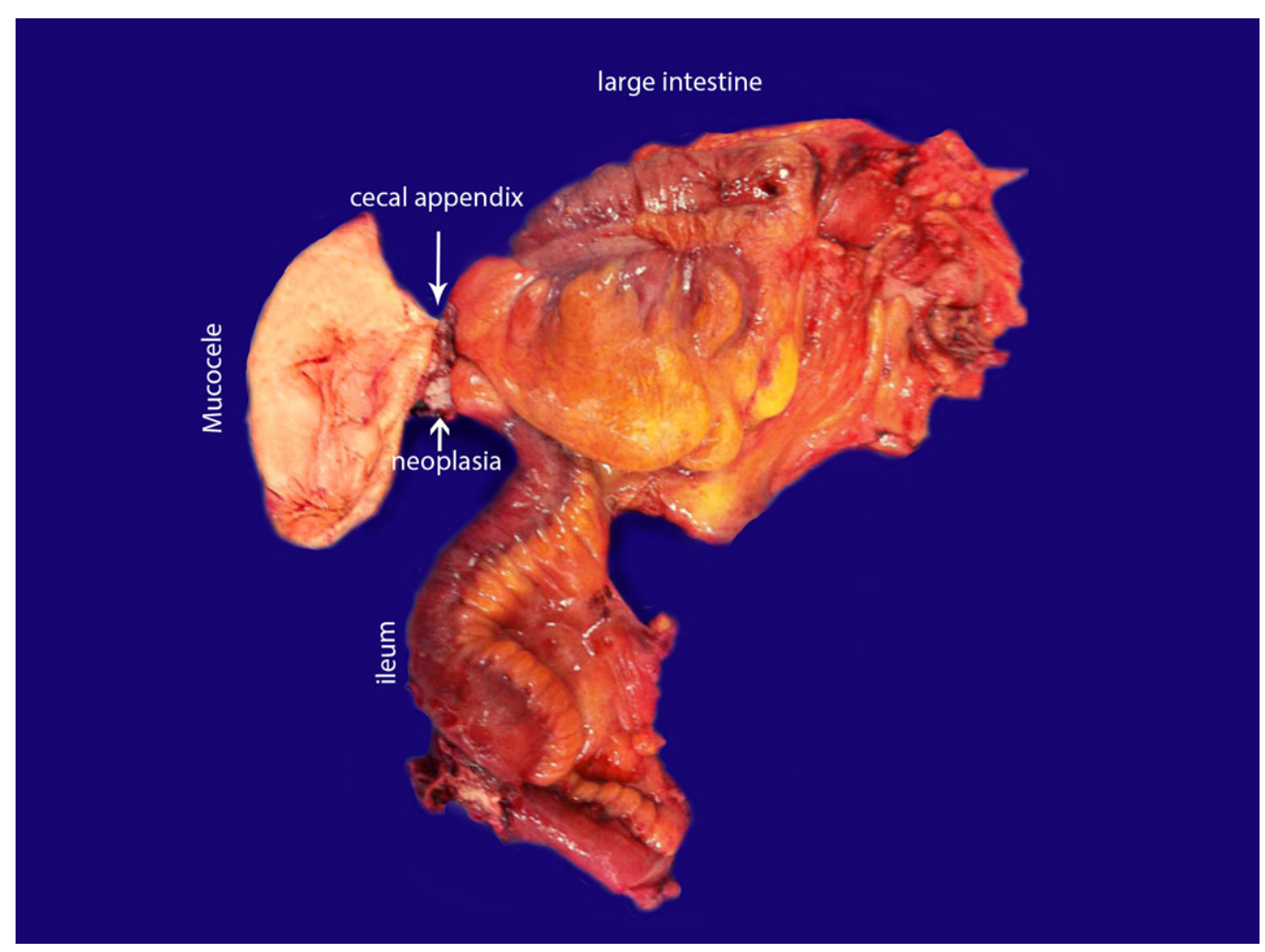

Figure 2 - Gross examination of the surgical specimen showing the opened mucole attached to the appendix. 
(WHO classification). Neoplastic infiltration reached the subserosa. Lymphatic invasion was present. Neoplasia was present in a fragment of fibroadipous tissue, which was sent separately from the whole surgical specimen. Surgical margins were tumorfree as well as 28 resected lymph nodes. Besides these findings, there was an acute appendicitis accompanied by wall perforation surrounded by granulation tissue and fibrosis. Dystrophic calcifications in the appendiceal wall were also present. (Figures 3, 4 and 5) The postoperative outcome was favorable, and the patient was discharged and referred to an oncologic center to follow complementary treatment.

\section{DISCUSSION}

Vermiform appendix is a very rare site of gastrointestinal malignancy accounting for $0.18 \%$ of all colorectal cancers. ${ }^{1,2}$ The diagnostic rate after appendectomies ranges between $0.03 \%$ and $2.2 \%{ }^{2,3,4}$ Among the appendiceal malignancies adenocarcinomas $(65.4 \%)$ are the most common, followed by neuroendocrine tumors (31.7\%), lymphomas $(1.7 \%)$, sarcomas and gastrointestinal stromal tumors (GISTs) $(<1 \%) .{ }^{5}$ The majority of appendiceal adenocarcinomas are well- differentiated mucinous adenocarcinomas. Less frequently, this group of neoplasia may also present as signet-ring cell carcinoma, small-cell carcinoma and undifferentiated carcinoma. ${ }^{5}$

The mucoceles arising from cystic mucinous neoplasms represent the most common presentation of appendiceal adenocarcinoma detected by imaging. ${ }^{6}$ The term "mucocele" is simply a macroscopic description of an appendix that is grossly distended by mucus; no matter the pathologic-causing entity. ${ }^{6}$ Besides the lymphatic and hematogeneous spreading vias, the adenocarcinomas can disseminate throughout the peritoneal cavity in the form of gelatinous deposits, termed "pseudomyxoma peritonei", resulting in a clinical picture in which the growth of neoplastic mucin-secreting cells within the peritoneal cavity produces a mucinous ascites or mucin deposits. ${ }^{7,8}$ According to histological featuring pseudomyxoma peritonei are classified as low grade or high-grade mucinous carcinoma peritonei, and represent a continuous spectrum. In general, low-grade pseudomyxoma peritonei is associated with lowgrade appendiceal mucinous neoplasms, while high-grade disease is associated with mucinous adenocarcinoma, but discordant cases can occur. $^{8,9}$ The old term disseminated peritoneal adenomucinous that has been used for low-grade

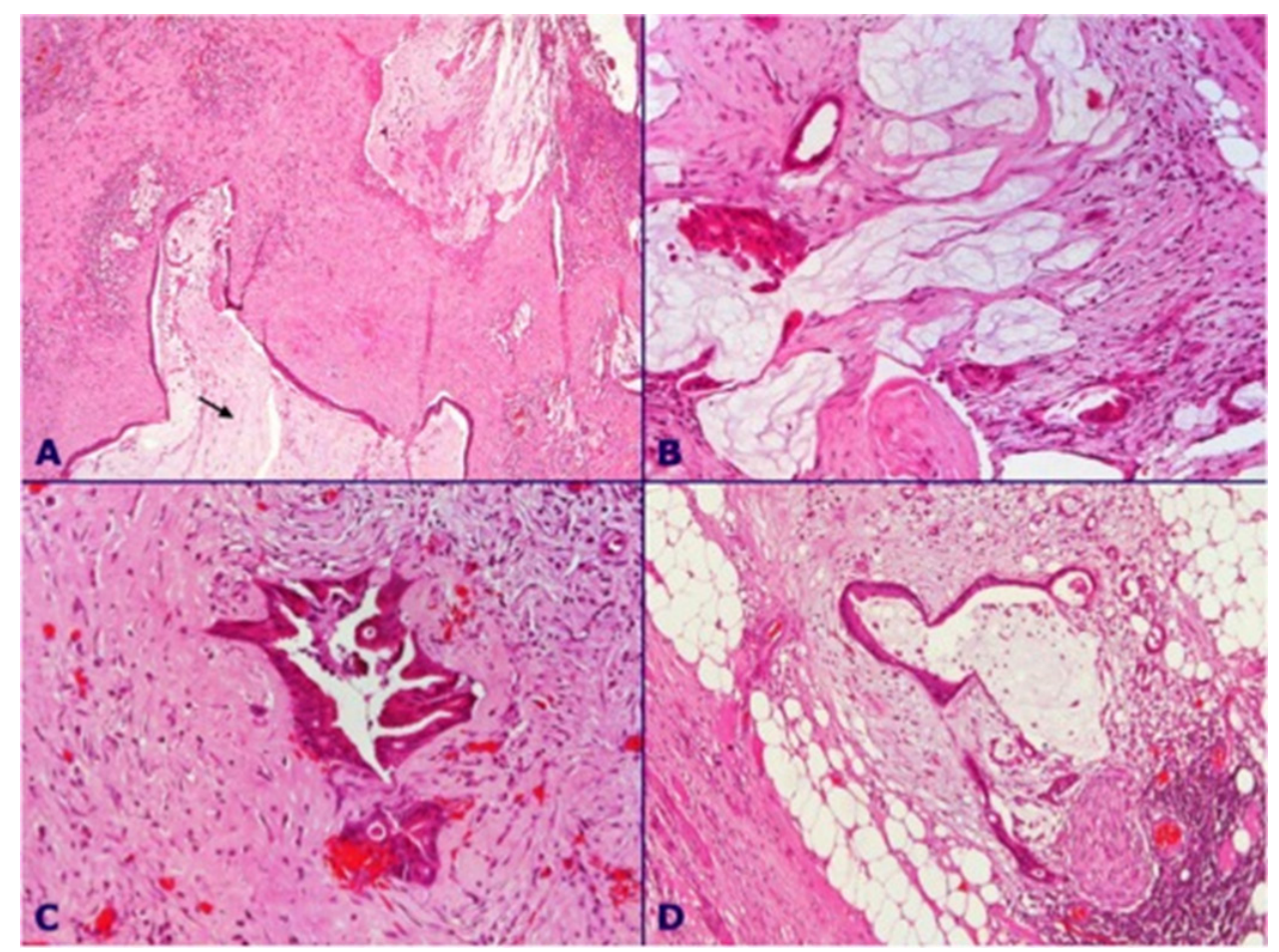

Figure $\mathbf{3}$ - Photomicrography of the appendix and the surrounding tissue. A - Overview of mucinous adenocarcinoma of the appendix ostium, with extensive areas of mucin (arrow) (HE 100X); B - Tubular architecture and infiltrative aspect of the invasive front of the tumor (HE 200X); C - Infiltrative atypical glands with intense peritumoral desmoplasia and mild inflammatory infiltrate (HE 400X); D - Infiltration of mucinous adenocarcinoma in the pericolic adipose tissue, with perineural invasion (HE 200X). 


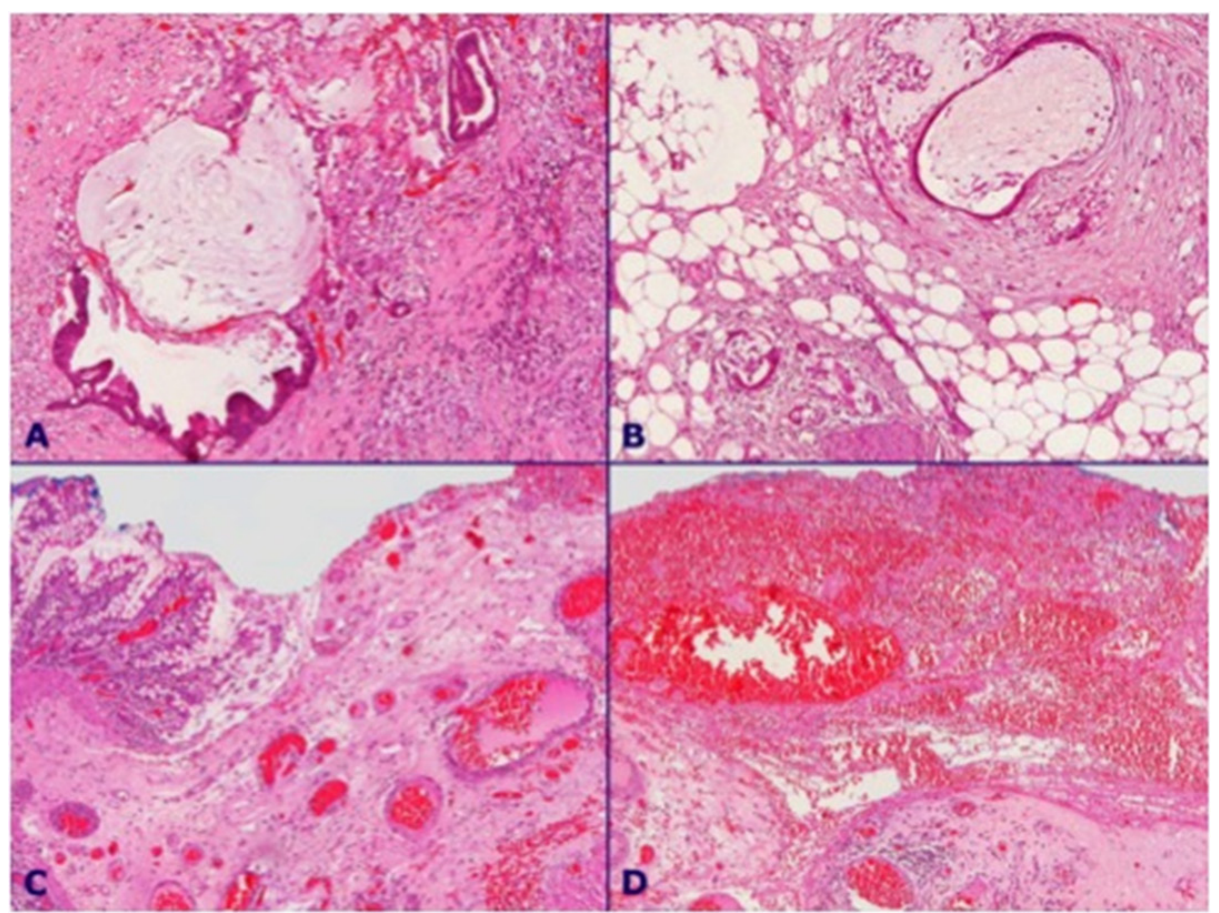

Figure 4-Photomicrography of the appendix and the surrounding tissue. A and B - Infiltration of peritonealized adipose tissue by mucinous adenocarcinoma of the appendix. Note the extensive areas of mucin (arrow) (HE 100X); C - Segment of ileum with ulceration and suppuration of the adjacent wall (HE 100X); D - Extensive acute purulent serositis in organization observed in the ileum, appendix, and right colon (HE 100X).

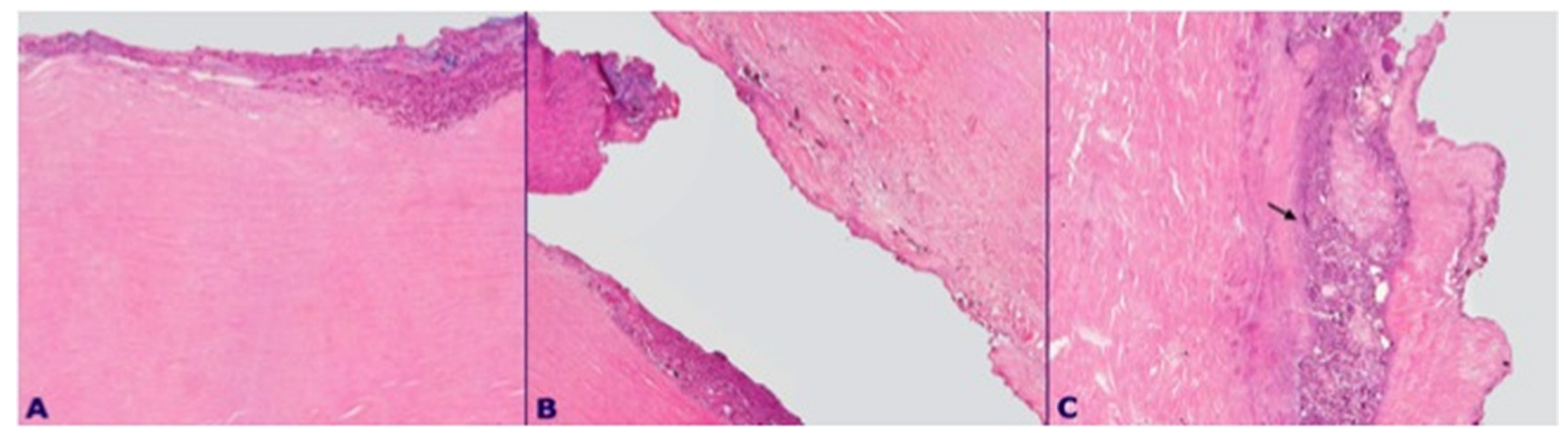

Figure 5 - Photomicrography of the appendix. A - Panoramic view of the appendix with appendicitis in organization and fibrosis (HE 100X); B - Areas of fibrin deposition in the mucosa of the appendix (HE 200X); C - Extensive areas of dystrophic calcification associated with fibrosis of the appendix wall (arrow) (HE 400X).

pseudomyxoma peritonei should be avoid. 8,10 Most cases of pseudomyxoma peritonei reflect the dissemination of an appendiceal mucinous neoplasm, although this entity is not synonymous with a neoplasm nor are all neoplastic cases. ${ }^{7}$ It can also be associated with mucinous tumors from other sites including the gallbladder, stomach, colon and rectum, pancreas, fallopian tube, lung, and breast. ${ }^{11}$ The ovary is only the primary source on the very rare occasions when a well-differentiate mucinous adenocarcinoma of intestinal type arises in a mature cystic teratoma. ${ }^{8}$

The mean age for the initial symptoms is 50 years $^{12}$ with a male predominance of $4: 1 .^{12}$ The majority of cases present as acute appendicitis due to appendiceal obstruction by the tumor's progressive growth. ${ }^{6}$ However, other less common forms of clinical presentation are also described, namely: non-tender abdominal mass, incidental imaging findings, intussusceptions, gastrointestinal bleeding, and ureteral obstruction. ${ }^{6}$ It can also be diagnosed incidentally after appendectomy. ${ }^{1}$ Carcinoma in situ in excised appendix has been reported. ${ }^{13}$

Because of the scarcity of early specific signs and symptoms characterizing the appendiceal adenocarcinomas at early stages, the diagnosis, in the vast majority of cases, are done in advanced stages. ${ }^{14}$ In a review of 258 cases reported in the Japanese literature, Yamasawa et al. ${ }^{15}$ found a frequency of early carcinoma in $13.6 \%$ (mucosal and submucosal carcinoma in 20 and 15 cases, 
respectively). In the case of female patients, the clinical presentation of the appendiceal adenocarcinoma may be ovarian involvement. ${ }^{16}$

In this case report, the neoplastic histological type was a mucinous adenocarcinoma accompanied by a mucocele, which permitted the imaging diagnosis. The age of the patient and the clinical presentation are in accordance with the literature. The acute appendicitis probably preceded the hospital admission. The ileal loop and peritoneum tamponade probably contained the inflammatory and infectious process, thereby postponing the search for medical care. The tumor size was small, neoplasia did not outpace the serosa, and the regional lymph nodes were free of tumor. By contrast, neoplasia was found in a fibroadipous tissue recovered by peritoneum, sent separately from the surgical specimen, which, unfortunately, characterized a T4a tumor staging. For this reason, this case has been considered as an advanced tumor for treatment and prognosis purposes.

The prognosis is poor in comparison with colon cancers arising from other portions of the intestine. ${ }^{17}$ This difference can be explained not only because the vast majority of appendiceal adenocarcinomas are diagnosed in advanced stages, but also because of anatomical features. The appendix has a rich lymphatic drainage and a relatively thin layer, facilitating regional lymph nodes and/or peritoneal cavity involvement. ${ }^{14}$ In a retrospective analysis of patients who underwent appendectomy between 1991 and 2007 in five centers in South Korea, Ko et al. ${ }^{17}$ described $47.3 \%$ of cases with localized disease, $9.1 \%$ with regional disease, and $43.6 \%$ with distant metastatic disease. In this study, the pathological stage of disease (distant vs loco-regional) was an independent predictor factor for overall survival.

Once the early diagnosis is the key point to a better outcome, the challenge to establish the preoperative diagnosis is constantly under investigation. Appendiceal tumors, in the early stage of development, are difficult to detect on routine computed tomography (CT) and colonoscopy. In this stage, these tumors are frequently asymptomatic. Trivedi et al. ${ }^{18}$ reported $3.1 \%$ of positivity for malignancy in preoperative colonoscopy biopsies of the appendix undertaken in patients with histologically confirmed appendiceal adenocarcinoma.

The CT images, which point to the possibility of appendiceal neoplasia, are: appendiceal dilation or mass in the topography of the appendix, and gross ascites with a mucinous component. ${ }^{19}$ Positron emission tomography is a recent and expensive diagnostic method, which still presents controversial efficacy for the early diagnosis of appendiceal adenocarcinoma. ${ }^{13}$

Because these tumors present a similar behavior of the colonic adenocarcinomas, they must also be treated with the same aggressive surgical approach. ${ }^{12}$ Right hemicolectomy with lymph nodes resection is the recommended treatment..$^{10}$ This extended resection is associated with a better survival rate compared with isolated appendectomy. ${ }^{20}$ Hesketh ${ }^{21}$ described a difference in the 5-year survival rate ranging from $20 \%$ after appendectomy alone to $63 \%$ when right hemicolectomy was undertaken. Recently, the study conducted by Turaga et al. ${ }^{22}$ with 2101 patients with the diagnosis of mucinous adenocarcinoma of the appendix concluded that: "right hemicolectomy may not add any therapeutic benefit in patients presenting with metastatic disease, visceral or nodal. In patients with high risk of nodal metastases, the rationale for staging is appropriate. A right hemicolectomy should be performed in the setting where the tumor cannot be cleared otherwise or the need for staging is strong enough to warrant the morbidity of the operation. Adjuvant therapy for appendiceal adenocarcinomas, similarly to colon adenocarcinomas, consists of $5-\mathrm{FU}$, either alone or in combination with a variety of other chemotherapeutic agents. ${ }^{23}$

Nonetheless, this case not only reminds us of the importance of this unusual diagnostic possibility, but also the mandatory thorough histopathological examinations after appendectomy, mainly when appendicitis is diagnosed in the adult or older group of patients.

\section{REFERENCES}

1. Koksal A, Kalkan IH, Yildiz H, Ökten RS, Neşşar G, Saşmaz N. Direct visualization of an extremely rare malignacy: Adenocarcinoma of the Appendix. Am J Gastroenterol. 2013;108:149-50. PMid:23287952. http:// dx.doi.org/10.1038/ajg.2012.339

2. Oya S, Miyata K, Yuasa N, et al. Early carcinoma of the appendix vermiformis. Dig Endosc. 2008;21:53-5. http:// dx.doi.org/10.1111/j.1443-1661.2008.00828.x

3. Connor SJ, Hanna GB, Frizelle FA. Appendiceal tumors: retrospective clinicopathologic analysis of appendiceal tumors from 7,970 appendectomies. Dis Colon Rectum. 1998;41:7580. PMid:9510314. http://dx.doi.org/10.1007/BF02236899 
4. Hananel N, Powsner E, Wolloch Y. Adenocarcinoma of the appendix: an unusual disease. Eur J Surg. 1998;164:859-62. PMid:9845132. http://dx.doi. org/10.1080/110241598750005282

5. Gustafsson B, Siddique L, Chan A, et al. Uncommon cancers of the small intestine, appendix and colon: An analysis of SEER 1973-2004, and current diagnosis and therapy. Int J Oncol. 2008;33:1121-31. PMid:19020744.

6. Pickhardt PJ, Levy AD, Rohrmann CA, et al. Primary neoplasms ofthe appendix: radiologic spectrum of disease with pathologic correlation. Radiographics. 2003;23:645-62. PMid:12740466. http://dx.doi.org/10.1148/rg.233025134

7. Panarelli N, Yantiss R. Mucinous neoplasms of the appendix and peritoneum. Arch Pathol Lab Med. 2011;135:1261-8. PMid:21970481. http://dx.doi.org/10.5858/arpa.2011-0034-RA

8. Carr NJ, Sobin LH. Adenocarcinoma of the appendix. In: Bosman FT, Carneiro F, Hruban RH, Theise ND, editors. WHO Classification of Tumors of the Digestive System. 4th ed. Lyon: IARC; 2010.

9. Bradley RF, Stewart JH, Russell GB, et al. Pseudomyxoma peritonei of appendiceal origin: a clinicopathologic analysis of 101 patients uniformly treated at a single institution, with literature review. Am J Surg Pathol. 2006;30:559. PMid:16699309. http://dx.doi.org/10.1097/01. pas.0000202039.74837.7d

10. Jackson SL, Fleming RA, Loggie BW, et al. Gelatinous ascites: a cytohistologic study of pseudomyxoma peritonei in 67 patients. Mod Pathol. 2001;14:664-71. PMid:11454998. http://dx.doi.org/10.1038/modpathol.3880370

11. Bevan K, Mohamed F, Moran B. Pseudomyxoma peritonei. World J Gastrointest Oncol. 2010;2:44-50. PMid:21160816 PMCid:2999154. http://dx.doi.org/10.4251/wjgo.v2.i1.44

12. Conte CC, Petrelli NJ, Stule J, et al. Adenocarcinoma of the appendix. Surg Gynecol Obstet.1988;166:451-3. PMid:2452489.

13. Koizumi N, Murayama Y, Kuriu Y. Incidentally Discovered Adenocarcinoma in situ of the Appendix in a Young Woman. Case Rep Gastroenterol. 2012;6:726-33. PMid:23275764 PMCid:3531942. http://dx.doi.org/10.1159/000345805
14. Benedix F, Reimer A, Gastinger I, et al. Primary appendiceal carcinoma? Epidemiology, surgery and survival: results of a German multi-center study. Eur J Surg Oncol. 2010;36:763-71. PMid:20561765. http://dx.doi.org/10.1016/j.ejso.2010.05.025

15. Yamasawa K, Saito $\mathrm{Y}$, Yano $\mathrm{H}$, et al. [An adenocarcinoma of the appendix, which was difficult to distinguish preoperatively from acute appendicitis with an abdominal abscess. A case report and review of thirteen cases of primary carcinoma of the appendix from our facilities]. Nippon Shokaki Geka Gakkai Zasshi. 2006;39:718-23. Japanese. http://dx.doi. org/10.5833/jjgs.39.718

16. Timofeev J, Galgano MT, Stoler MH, et al. Appendiceal pathology at the time of oophorectomy for ovarian neoplasms. Obstet Gynecol. 2010 116:1348-53. PMid:21099601. http:// dx.doi.org/10.1097/AOG.0b013e3181fae628

17. Ko YH, Park SH, Jung CK, et al. Clinical characteristics and prognostic factors for primary appendiceal carcinoma. Asia Pac J Clin Oncol. 2010; 6:19- 27. PMid:20398034. http:// dx.doi.org/10.1111/j.1743-7563.2010.01276.x

18. Trivedi AN, Levine EA, Mishra G. Adenocarcinoma of the appendix is rarely detected by colonoscopy. J Gastrointest Surg. 2009;13: 668-75. PMid:19089515. http://dx.doi. org/10.1007/s11605-008-0774-6

19. Shankar S, Ledakis $P$, Halabi $H$. Neoplasms of the appendix. Hematol Oncol Clin N Am. 2012; 26: 1261-90. PMid:23116580. http://dx.doi.org/10.1016/j.hoc.2012.08.010

20. Lo NS, Sarr MG. Mucinous cystadenocarcinoma of the appendix. The controversy persists: a review. Hepatogastroenterology. 2003;50:432-7. PMid:12749241.

21. Hesketh KT. The management of primary adenocarcinoma of the vermiform appendix. Gut. 1963;4:158-68. PMid:13954206 PMCid:1413434. http://dx.doi.org/10.1136/gut.4.2.158

22. Turaga KK, Pappas S, Gamblin TC. Right hemicolectomy for mucinous adenocarcinoma of the appendix: just right or too much? Ann Surg Oncol. 2013;20:1063-7. http://dx.doi. org/10.1245/s10434-012-2783-7

23. O'Donnell ME, Badger SA, Beattie GC, et al. Malignant neoplasms of the appendix. Int J Colorectal Dis. 2007;22:123948 . PMid:17447078. http://dx.doi.org/10.1007/s00384-0070304-0

\section{Conflict of interest: None}

Submitted on: $5^{\text {th }}$ January 2013

Accept on: $25^{\text {th }}$ May 2013

Correspondence: Hospital das Clínicas da Universidade de São Paulo

Av. Dr. Enéas Carvalho de Aguiar, 255 - São Paulo/SP - Brazil

CEP: 05403-000 - Phone: +55 (11) 2661-7690

E-mail: mi.rfc@uol.com.br 